\title{
Subtle Right Ventricular Affection in Patients with Acute Myocardial Infarction, Echocardiographic Assessment
}

\author{
Abdallah Mohamed*, Shaaban Alramlawy, Samir El-Hadidy, Mohamed Ibrahiem Affify, Waheed Radwan \\ Department of Critical Care Medicine, Faculty of Medicine, Cairo University, Giza, Egypt
}

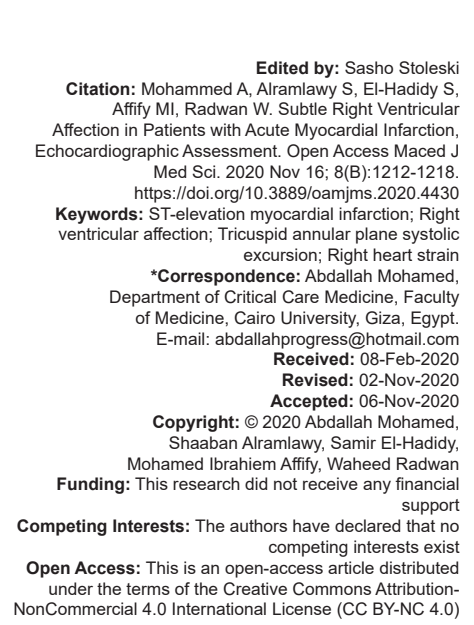

Introduction

The right ventricle (RV) has historically received less attention than its counterpart of the left side of the heart, yet there is a substantial body of evidence showing that RV size and function are perhaps equally important in predicting adverse outcomes in cardiovascular disease [1].

Ventricular interdependence refers to the concept that the size, shape, and compliance of one ventricle may affect the size, shape, and pressurevolume relationship of the other ventricle through direct mechanical interactions. Although always present, ventricular interdependence is most apparent with changes in loading conditions such as those seen with respiration or sudden postural changes. Ventricular interdependence plays an essential part in the pathophysiology of RV dysfunction [1]. Systolic ventricular interdependence is mediated mainly through the interventricular septum. The pericardium may not be as important for systolic ventricular interdependence as it is for diastolic ventricular interdependence.

Acute myocardial infarction (AMI) is associated with early and late compensatory mechanisms which can be seen as attempts to optimize ventricular filling and cardiac output of both the left ventricle (LV) and RVs [2].

Cardiac enlargement after a myocardial infarction (MI) is an ominous finding that is associated with distinctly reduced survival. Recently, interest has developed in limiting ventricular remodeling, with the objective of improving ventricular function and clinical outcome [3]. However, studies concerning RV remodeling are few and the extent, time, and causes for $\mathrm{RV}$ dilatation and dysfunction remain unclear.

The RV can be studied with many imaging and functional modalities. In clinical practice, echocardiography is the mainstay of evaluation of RV structure and function. Compared with other modalities, it offers the advantages of versatility and availability. Furthermore, Doppler-derived indices of RV function, such as the myocardial performance index and tricuspid annular isovolumic acceleration, are emerging as promising parameters of RV function [4]

No single method can give us all information and reliability about the RV; however, if some were done collectively with clinical history and examination, this will be better and more evident. 


\section{Methods}

The study was done on 80 patients who had acute left ventricle ST elevated myocardial infarction (LV STEMI) and subjected to primary percutaneous coronary intervention $\left(1^{\text {ry }} \mathrm{PCl}\right)$. The study was done in Cairo University, critical care department. All patients were studied within 2 days after $1^{\text {ry }} \mathrm{PCl}$.

We excluded all patients with:

1. RV infarction.

2. Moderate to severe tricuspid regurgitation.

3. Pulmonary hypertension; $\mathrm{PH}$ was defined as an estimated pulmonary artery systolic pressure $(\mathrm{PASP}) \geq 40 \mathrm{mmHg}$ [5].

4. Chronic pulmonary disease.

5. Dilated cardiomyopathy.

6. Atrial septal defect and ventricular septal defect.

7. Cardiac dysrhythmias.

Medical history and detailed physical examination were done for all patients. Routine laboratory tests, including cardiac enzymes, were obtained.

\section{Echocardiography}

The routine formal study was done with the assessment of: Right ventricular (RV) systolic function using: Tricuspid annular plane systolic excursion (TAPSE), the normal reference limits being a TAPSE of $\geq 1.7 \mathrm{~cm}[6]$.

Peak systolic longitudinal strain of the RV free wall using speckle-tracking strain echocardiography, $\mathrm{RV}$ longitudinal strain of magnitude less negative than $-20 \%$ is likely abnormal [7].

Left ventricular peak systolic strains in the longitudinal direction using speckle-tracking strain echocardiography, normal values for left strain measurement is $-19.9 \pm 5.3 \%$ for longitudinal strain [8].

Estimated peak systolic pulmonary artery pressure $(\mathrm{PH})$ was defined as an estimated PASP $\geq 40$ $\mathrm{mmHg}$. Patients with pulmonary hypertension were excluded from the study.

The 17-segment regional wall motion scoring index (RWMSI) was calculated.

The study was conducted using an iE33 PHILIPS colored echocardiographic machine using a 3.5 $\mathrm{MHz}$ transducer (Figures 1 and 2).

Finally, we followed the course of the patient regarding the occurrence of in-hospital complications, duration of stay in the intensive care unit (ICU), in-hospital, 30-day, and 1-year mortality.

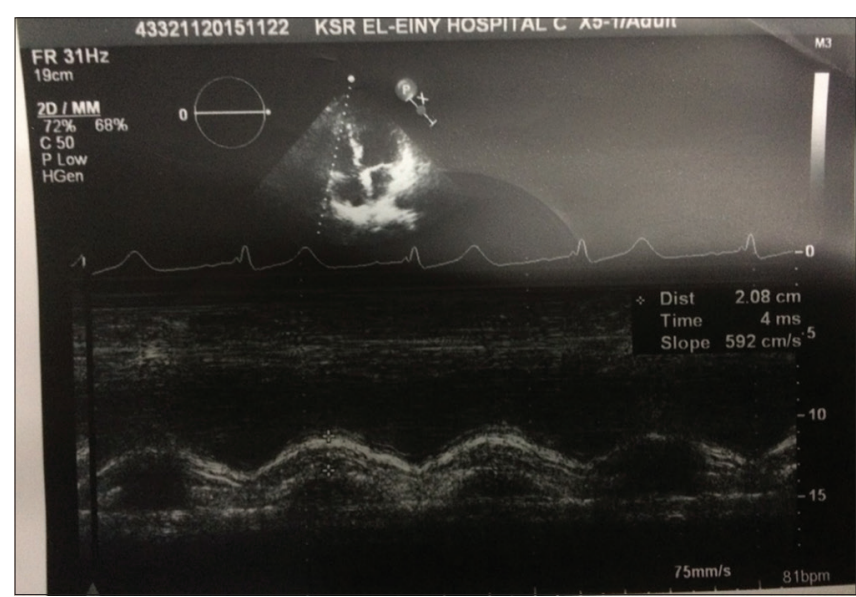

Figure 1: Tricuspid annular plane systolic excursion

\section{Statistical Analysis}

Data were coded and entered using the Statistical Package for the Social Sciences version 24.

Data were arranged using mean, standard deviation, median, minimum, and maximum in quantitative data and using frequency (count) and relative frequency (percentage) for categorical data.

Comparisons between quantitative data were done using the Mann-Whitney test and for categorical data, Chi-square test was done. Exact test was used instead when the expected frequency is $<5$. $p<0.05$ are statistically significant.

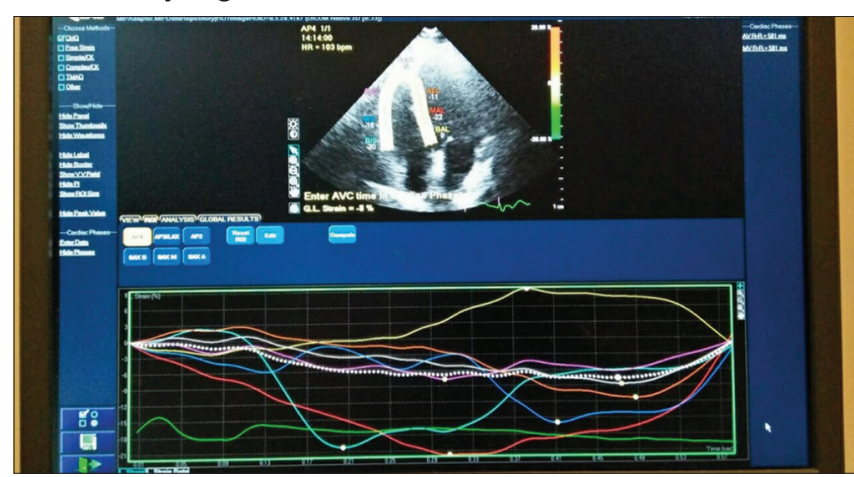

Figure 2: Right ventricular longitudinal strain by speckle tracking echocardiography

\section{Results}

In our study, 80 patients (64 men and 16 women) aged 55 years admitted to ICU with acute STEMI and subjected with primary $\mathrm{PCl}$.

In our study, risk factors are distributed as in (Table 1). The mean duration of ICU stay was $6.4 \pm 2.5$ days (Table 2). During hospitalization, 28 (35\%) patients developed in-hospital complications (cardiogenic shock, arrhythmias, and recurrent ischemia) while the 


\section{Table 1: Risk factors}

\begin{tabular}{lll}
\hline Risk factors & Count & $\%$ \\
\hline DM & & \\
$\quad$ DM & 34 & 42.5 \\
$\quad$ Not diabetic & 46 & 57.5 \\
Hypertension & & \\
$\quad$ Hypertensive & 26 & 32.5 \\
$\quad$ Normotensive & 54 & 67.5 \\
Smoking & & \\
$\quad$ Smoker & 64 & 80.0 \\
$\quad$ Not smoker & 16 & 20.0 \\
Dyslipidemia & & \\
$\quad$ Dyslipidemia & 46 & 57.5 \\
$\quad$ Normal & 34 & 42.5 \\
Ischemic heart disease (previous acute coronary syndrome) & & \\
$\quad$ Positive history & 16 & 20.0 \\
$\quad$ No history & 64 & 80.0 \\
Family history & & \\
$\quad$ Positive history & 32 & 40.0 \\
$\quad$ No history & 48 & 60.0 \\
\hline DM: Diabetes mellitus & &
\end{tabular}

Table 2: Duration of intensive care unit stay

\begin{tabular}{llllll}
\hline Parameters & Mean & Standard deviation & Median & Minimum & Maximum \\
\hline Intensive care & 6.4 & 2.5 & 6.00 & 3.00 & 18.00
\end{tabular}

unit stay (days)

rest of the patients had a smooth course (Table 3 ).

Table 3: Incidence of in-hospital complications

\begin{tabular}{lll}
\hline Parameters & Count & $\%$ \\
\hline (In-hospital complications) & 28 & 35.0 \\
\hline
\end{tabular}

No documented in-hospital and 30-day mortality while on 1-year assessment, 4 mortalities were identified (Table 4).

Table 4: The mortality

\begin{tabular}{lll}
\hline Mortality & Count & $\%$ \\
\hline In-hospital mortality & & \\
$\quad$ Non-survivors & 0 & 0.0 \\
$\quad$ Survivors & 80 & 100.0 \\
30-day mortality & & \\
$\quad$ Non-survivors & 0 & 0 \\
$\quad$ Survivors & 80 & 100.0 \\
1-year mortality & & 5.0 \\
$\quad$ Non-survivors & 4 & 95.0 \\
$\quad$ Survivors & 76 & \\
\hline
\end{tabular}

\section{Coronary angiographic data}

Infarct-related artery (IRA) was left anterior descending artery in $60(75 \%)$ patients, right coronary artery in $16(20 \%)$ patients, and left circumflex artery in only $4(5 \%)$ patients. We found that thrombolysis in MI flow was 0 (pre $\mathrm{PCl}$ ) and became II (post-PCl) in $18(22.5 \%)$ patients and III (post-PCI) in 62(77.5\%) patients (Table 5).

\section{Echocardiography data}

The mean left ventricular end-diastolic diameter was $62.53 \pm 30.42 \mathrm{~mm}$ and the mean left ventricular end-systolic diameter was $38.96 \pm 16.32$ $\mathrm{mm}$. Left ventricular ejection fraction (LVEF) was

Table 5: Coronary angiographic data

\begin{tabular}{lll}
\hline Parameters & Count & $\%$ \\
\hline Infarct related artery & & \\
Left anterior descending artery & 60 & 75 \\
$\quad$ Left circumflex artery & 4 & 5.0 \\
Right coronary artery & 16 & 20.0 \\
Post percutaneous coronary intervention TIMI flow grade & & \\
TIMI flow II & 18 & $22.5 \%$ \\
TIMI flow III & 62 & $77.5 \%$ \\
\hline TIMI: Thrombolysis in myocardial infarction &
\end{tabular}

$47.45 \% \pm 10.44$ (Table 3). There were 46 (57.5\%) patients with LV diastolic dysfunction Grade I and 34 (42.5\%) patients with LV diastolic dysfunction Grade II. The 17-Segment Regional Wall Motion Scoring Index was calculated and the mean of our patients was 1.51 \pm 0.25 (Table 5)

Regarding the RV dimensions, we measured the RV mid-cavity dimension and the mean was $2.43 \pm$ $0.25 \mathrm{~cm}$. The TAPSE of our patients was $1.8 \pm 0.34 \mathrm{~cm}$ (Table 5).

Regarding Speckle tracking echocardiography, we assessed the global longitudinal strains of the LV and RV using speckle tracking echocardiography, the mean LV longitudinal strain was $-14.55 \pm 4.84 \%$, and the mean RV longitudinal strain was $-15.7 \pm 5.06 \%$ (Table 6).

\section{Table 6: Echocardiography parameters}

\begin{tabular}{llllll}
\hline Parameters & Mean & $\begin{array}{l}\text { Standard } \\
\text { deviation }\end{array}$ & Median & Minimum & Maximum \\
\hline LV end-diastolic diameter $(\mathrm{mm})$ & 62.53 & 30.42 & 50.20 & 40.40 & 135.00 \\
LV end-systolic diameter $(\mathrm{mm})$ & 38.96 & 16.32 & 30.60 & 20.30 & 75.00 \\
LV systolic function (EF \%) & 47.45 & 10.44 & 46.00 & 25.00 & 78.00 \\
Regional wall motion scoring index & 1.51 & 0.025 & 1.55 & 1.00 & 2.00 \\
RV TAPSE & 1.80 & 0.34 & 1.70 & 1.40 & 3.00 \\
RV dimensions & 2.43 & 0.25 & 2.45 & 1.70 & 2.90 \\
LV longitudinal strain & -14.55 & 4.84 & -13.50 & -23.00 & -8.00 \\
RV longitudinal strain & -15.70 & 5.06 & -15.00 & -26.00 & -8.00 \\
\hline LV: Left ventricle, RV TAPSE: Right ventricle tricuspid annular plane systolic excursion, EF: Ejection fraction
\end{tabular}

On determining the incidence of RV dysfunction among these patients, we found that there were 38 (47.5\%) patients with TAPSE <1.7 cm and $48(60 \%)$ patients with RV longitudinal strain less negative than $-19 \%$ (Table 7 and Figure 3).

Table 7: Incidence of right ventricular dysfunction in patients with acute ST elevated myocardial infarction after $1^{\text {ry }}$ percutaneous coronary intervention (by echocardiography)

\begin{tabular}{lll}
\hline Parameters & Count & $\%$ \\
\hline Tricuspid annular plane systolic excursion & & \\
$\quad<1.7$ & 38 & 47.5 \\
$\geq 1.7$ & 42 & 52.5 \\
Right heart strain & 48 & \\
$<-19$ & 32 & 60.0 \\
$\geq-19$ & 40.0 \\
\hline
\end{tabular}

On studying the relationship between the site of $\mathrm{Ml}$ and the RV affection, there was a statistically significant relationship between patients with anterior $\mathrm{MI}$ and RV dysfunction ( $p=0.004)$ (Table 8).

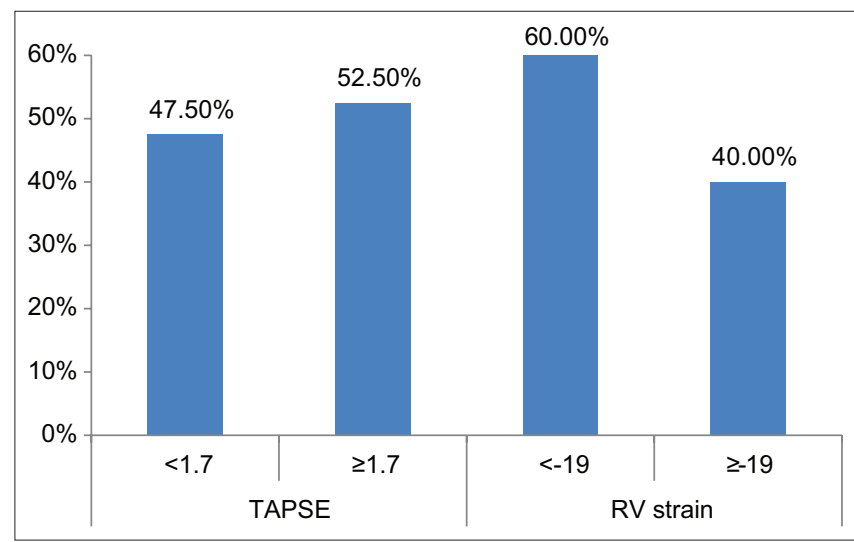

Figure 3: Incidence of right ventricular dysfunction in patients with acute ST-elevation myocardial infarction after $1^{\text {ty }}$ percutaneous coronary intervention 
Table 8: Right ventricular affection and site of MI

\begin{tabular}{|c|c|c|c|c|c|}
\hline \multirow[t]{3}{*}{ Parameters } & \multicolumn{4}{|c|}{ Site of MI (electrocardiogram) } & \multirow[t]{3}{*}{$p$ value } \\
\hline & \multicolumn{2}{|c|}{ Inferior } & \multicolumn{2}{|c|}{ Anterior } & \\
\hline & Count & $\%$ & Count & $\%$ & \\
\hline \multicolumn{6}{|c|}{ Tricuspid annular plane systolic excursion } \\
\hline$<1.7$ & 4 & 20.0 & 34 & 56.7 & 0.004 \\
\hline$\geq 1.7$ & 16 & 80.0 & 26 & 43.3 & \\
\hline \multicolumn{6}{|c|}{ Right heart strain } \\
\hline$<-19$ & 10 & 50.0 & 38 & 63.3 & 0.292 \\
\hline$\geq-19$ & 10 & 50.0 & 22 & 36.7 & \\
\hline
\end{tabular}

Furthermore, on studying the relationship between the IRA and the RV dysfunction, there was a statistically significant relationship between patients with IRA LAD and RV dysfunction ( $p=0.009)$ (Table 9).

Table 9: Right ventricular affection and IRA

\begin{tabular}{|c|c|c|c|c|c|c|c|}
\hline \multirow[t]{3}{*}{ Parameters } & \multicolumn{6}{|l|}{ IRA } & \multirow[t]{3}{*}{$p$ value } \\
\hline & \multicolumn{2}{|c|}{$\begin{array}{l}\text { Left anterior } \\
\text { descending artery }\end{array}$} & \multicolumn{2}{|c|}{$\begin{array}{l}\text { Left circumflex } \\
\text { artery }\end{array}$} & \multicolumn{2}{|c|}{$\begin{array}{l}\text { Right coronary } \\
\text { artery }\end{array}$} & \\
\hline & Count & $\%$ & Count & $\%$ & Count & $\%$ & \\
\hline \multicolumn{8}{|c|}{ Tricuspid annular plane systolic excursion } \\
\hline$<1.7$ & 34 & 56.7 & 0 & 0 & 4 & 25.0 & \multirow[t]{2}{*}{0.009} \\
\hline$\geq 1.7$ & 26 & 43.3 & 4 & 100.0 & 12 & 75.0 & \\
\hline \multicolumn{8}{|c|}{ Right heart strain } \\
\hline$<-19$ & 38 & 63.3 & 0 & 0.0 & 10 & 62.5 & \multirow[t]{2}{*}{0.054} \\
\hline$\geq-19$ & 22 & 36.7 & 4 & 100.0 & 6 & 37.5 & \\
\hline
\end{tabular}

There was a significant statistical relationship between RT ventricular dysfunction (as assessed by TAPSE and RV longitudinal strain) and the duration of ICU stay, we observed that patients with RV dysfunction had a prolonged ICU stay, $p<0.001$ (Table 10 and Figure 4).

Table 10: Right ventricular affection and duration of ICU stay

\begin{tabular}{|c|c|c|c|c|c|c|}
\hline \multirow[t]{2}{*}{ Parameters } & \multicolumn{5}{|c|}{ ICU stay (days) } & \multirow[t]{2}{*}{$\mathrm{p}$ value } \\
\hline & Mean & Standard deviation & Median & Minimum & Maximum & \\
\hline \multicolumn{6}{|c|}{ Tricuspid annular plane systolic excursion } & \multirow{3}{*}{$<0.001$} \\
\hline$<1.7$ & 7.47 & 3.03 & 7.00 & 3.00 & 18.00 & \\
\hline$\geq 1.7$ & 5.52 & 1.54 & 5.00 & 3.00 & 9.00 & \\
\hline \multicolumn{6}{|c|}{ Right heart strain } & \\
\hline$<-19$ & 7.21 & 2.84 & 7.00 & 3.00 & 18.00 & \multirow[t]{2}{*}{$<0.001$} \\
\hline$\geq-19$ & 5.31 & 1.40 & 5.00 & 3.00 & 8.00 & \\
\hline
\end{tabular}

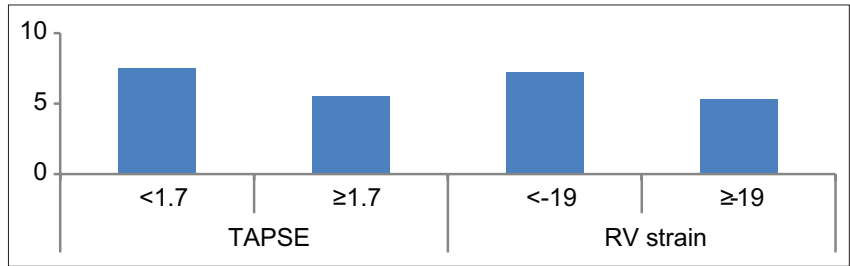

Figure 4: Right ventricular affection and duration of intensive care unit stay

It was found that RV dysfunction in our patients was related to the impairment of LV systolic function $(p<0.001)$ (Table 11 and Figure 5) and to the RWMSI; the larger RWMSI value, the more RV affection $(p<0.001)$ (Table 12).

Table 11: Right ventricular affection and impairment of LV systolic function EF \%

\begin{tabular}{|c|c|c|c|c|c|c|}
\hline \multirow[t]{2}{*}{ Parameters } & \multicolumn{5}{|c|}{ LV systolic function (EF \%) } & \multirow[t]{2}{*}{$p$ value } \\
\hline & Mean & Standard deviation & Median & Minimum & Maximum & \\
\hline \multicolumn{7}{|c|}{ Tricuspid annular plane systolic excursion } \\
\hline$<1.7$ & 40.21 & 6.15 & 41.00 & 25.00 & 47.00 & \multirow[t]{2}{*}{$<0.001$} \\
\hline$\geq 1.7$ & 54.00 & 9.15 & 51.00 & 40.00 & 78.00 & \\
\hline \multicolumn{7}{|c|}{ Right heart strain } \\
\hline$<-19$ & 42.96 & 8.77 & 42.50 & 25.00 & 64.00 & \multirow[t]{2}{*}{$<0.001$} \\
\hline$\geq-19$ & 54.19 & 9.22 & 51.00 & 45.00 & 78.00 & \\
\hline
\end{tabular}

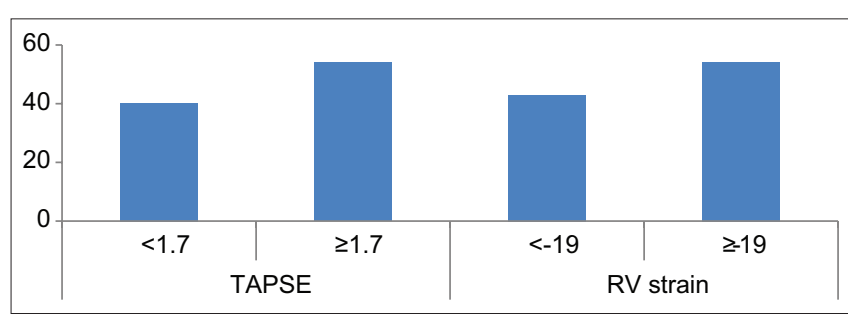

Figure 5: Right ventricular affection and impairment of left ventricular systolic function (ejection fraction \%)

Table 12: Right ventricular affection and RWMSI

\begin{tabular}{|c|c|c|c|c|c|c|}
\hline \multirow[t]{2}{*}{ Parameters } & \multicolumn{5}{|c|}{ RWMSI } & \multirow[t]{2}{*}{ p value } \\
\hline & Mean & Standard deviation & Median & Minimum & Maximum & \\
\hline \multicolumn{7}{|c|}{ Tricuspid annular plane systolic excursion } \\
\hline$<1.7$ & 1.70 & 0.14 & 1.70 & 1.47 & 2.00 & \multirow[t]{2}{*}{$<0.001$} \\
\hline$\geq 1.7$ & 1.35 & 0.20 & 1.30 & 1.00 & 1.80 & \\
\hline \multicolumn{7}{|c|}{ Right heart strain } \\
\hline$<-19$ & 1.63 & 0.22 & 1.70 & 1.20 & 2.00 & \multirow[t]{2}{*}{$<0.001$} \\
\hline$\geq-19$ & 1.35 & 0.19 & 1.35 & 1.00 & 1.64 & \\
\hline
\end{tabular}

There was a statistically significant relationship between RT ventricular dysfunction and in-hospital complications ( $p<0.001$ ) (Table 13 and Figure 6). Furthermore, there was a significant relationship between RV dysfunction and the 1-year mortality $(p=0.047)$ (Table 14 and Figure 7 ).

Table 13: Relation of right ventricular affection and in-hospital complications

\begin{tabular}{|c|c|c|c|c|c|}
\hline \multirow{3}{*}{ Parameters } & \multicolumn{4}{|c|}{ (In-hospital complications) } & \multirow{3}{*}{$p$ value } \\
\hline & \multicolumn{2}{|l|}{ Yes } & \multicolumn{2}{|l|}{ No } & \\
\hline & Count & $\%$ & Count & $\%$ & \\
\hline \multicolumn{6}{|c|}{ Tricuspid annular plane systolic excursion } \\
\hline$<1.7$ & 22 & 78.5 & 16 & 30.7 & \multirow[t]{2}{*}{$<0.001$} \\
\hline$\geq 1.7$ & 6 & 21.5 & 36 & 69.3 & \\
\hline \multicolumn{6}{|c|}{ Right heart strain } \\
\hline$<-19$ & 26 & 92.9 & 22 & 42.3 & \multirow[t]{2}{*}{$<0.001$} \\
\hline$\geq-19$ & 2 & 7.1 & 30 & 57.7 & \\
\hline
\end{tabular}

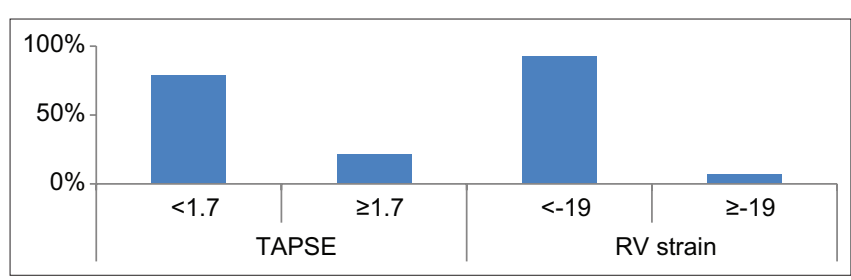

Figure 6: Relation of right ventricular affection and occurrence of in-hospital complications

There was a statistically significant cor relationship between $\mathrm{RV}$ longitudinal strain and RV-TAPSE as two echocardiographic methods for RV systolic function assessment $(r=0.792$ and $p<0.001)$ (Table 15 and Figure 8).

Table 14: Right ventricular affection and 1-year mortality

\begin{tabular}{|c|c|c|c|c|c|}
\hline \multirow[t]{3}{*}{ Parameters } & \multicolumn{4}{|c|}{ 1-year mortality } & \multirow{3}{*}{$\mathrm{p}$ value } \\
\hline & \multicolumn{2}{|l|}{ Alive } & \multicolumn{2}{|l|}{ Dead } & \\
\hline & Count & $\%$ & Count & $\%$ & \\
\hline \multicolumn{6}{|c|}{ Tricuspid annular plane systolic excursion } \\
\hline$<1.7$ & 34 & 44.7 & 4 & 100.0 & \multirow[t]{2}{*}{0.047} \\
\hline$\geq 1.7$ & 42 & 55.3 & 0 & 0.0 & \\
\hline \multicolumn{6}{|c|}{ Right heart strain } \\
\hline$<-19$ & 44 & 57.8 & 4 & 100.0 & \multirow[t]{2}{*}{0.146} \\
\hline$\geq-19$ & 32 & 42.2 & 0 & 0.0 & \\
\hline
\end{tabular}


Table 15: Cor relationship between RV longitudinal strain and RV-TAPSE as two methods for RV systolic function assessment

\begin{tabular}{ll}
\hline Parameters & RV-TAPSE \\
\hline RV longitudinal strain & \\
Correlation coefficient ( $r)$ & 0.792 \\
p value & $<0.001$ \\
$\mathrm{n}$ & 40 \\
\hline RV-TAPSE: Right ventricular-tricuspid annular plane systolic excursion &
\end{tabular}

\section{Discussion}

In 1616, Sir William Harvey was the first to describe the importance of RV function [1].

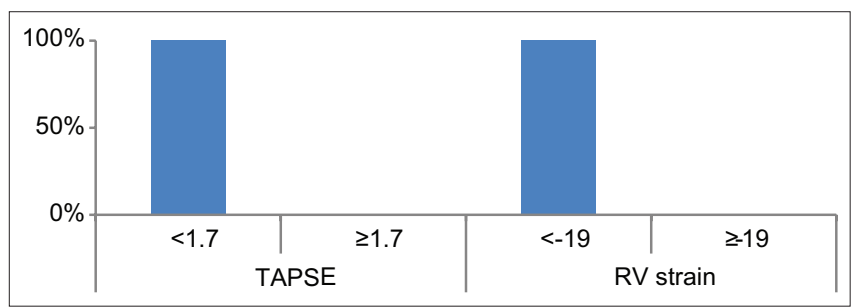

Figure 7: Right ventricular affection and 1-year mortality

The LV and RV are working as a "functional syncytium" and the two ventricles cannot be dissociated in an independent manner since the architecture of the distinct myocardial bands makes it mandatory for an integrated and unified function of both chambers.

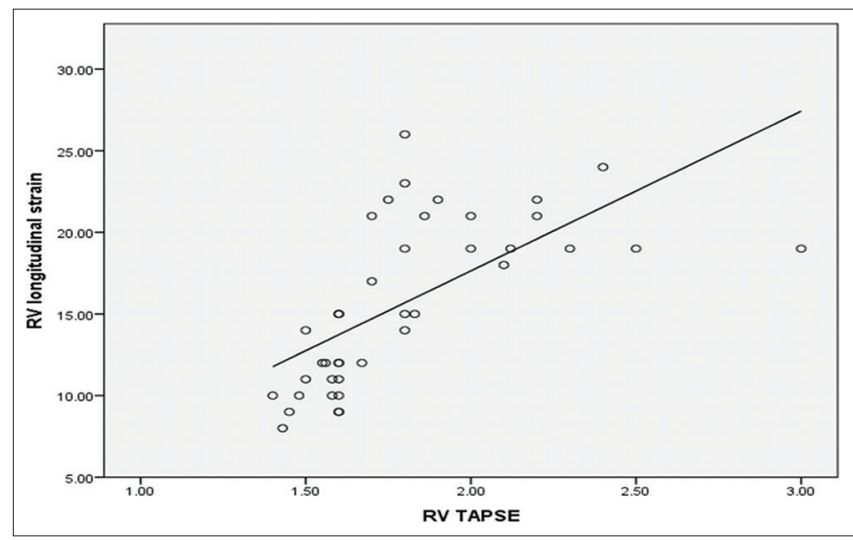

Figure 8: Correlation between right ventricular (RV) longitudinal strain and RV-tricuspid annular plane systolic excursion as two methods for $R V$ systolic function assessment

TAPSE is frequently used measurement to assess RV function and reflects the longitudinal systolic excursion of the lateral tricuspid valve annulus. It is easily obtained and has been shown to have robust diagnostic and prognostic value in several disease states. The primary challenge and main limitation of fractional area change (FAC) is the accurate identification and tracing of the true RV endocardial border rather than the prominent trabeculations and muscle bands [9]. On the other side, TAPSE measurement is not dependent on either geometric assumptions or traceable endocardial edges.

Strain is a novel technique that enables the angle-independent measurement of active myocardial deformation. Peak RV longitudinal strain, which quantifies the maximal shortening in the RV free wall from apex to base, is likely to be a good estimator of RV function because $80 \%$ of the stroke volume is generated by longitudinal shortening of the RV free wall [10].

In our study on determining the incidence of RV dysfunction among the patients with acute $\mathrm{MI}$ after $1^{\text {ry }} \mathrm{PCl}$, we found that there were $38(47.5 \%)$ patients with TAPSE $<1.7 \mathrm{~cm}$ and $48(60 \%)$ patients with RV longitudinal strain less negative than $-19 \%$. Thomas et al. 2016 [11] conducted a prospective study to assess RV function in patients with acute $\mathrm{Ml}$ treated with primary $\mathrm{PCl}$. They found that there were $(5.2 \%)$ of patients had reduced TAPSE, (32\%) patients had RV free wall longitudinal strain (FWLS) $<-20 \%$, and 15 patients (11\%) had RV FWLS $<-15 \%$ within 1.6 (interquartile range 1.4-2.5) days after STEMI. Keren Shahar et al. in 2016 [12] studied 1044 patients with acute MI. RV systolic function was assessed qualitatively by integrating visual assessment of the contractility of the RV walls from different views and quantitatively by calculating the RV FAC. Patients were classified into 4 groups according to the presence or absence of RV dysfunction and pulmonary hypertension; normal RV without pulmonary hypertension ( $\mathrm{n}=509$ ), normal $\mathrm{RV}$ and pulmonary hypertension ( $\mathrm{n}=373$ ), RV dysfunction without pulmonary hypertension ( $n=64$ ), and RV dysfunction and pulmonary hypertension ( $n=98)$.

On studying the relationship between the site of $\mathrm{MI}$ and the RV dysfunction, there was a statistically significant relationship between patients with anterior $\mathrm{MI}$ and RV dysfunction ( $p=0.004)$. Furthermore, there was a statistically significant relationship between patients with IRA LAD and RV dysfunction ( $p=0.009)$.

This disagrees with the results of Alam et al. in year 2000 [13], in which they prospectively compared the RV function between 38 patients with a first acute inferior MI, 33 patients with a first anterior MI, and 24 age-matched healthy individuals, they found that the peak systolic velocity of the tricuspid annulus was significantly reduced in inferior $\mathrm{MI}$ compared with that in healthy individuals (12 vs. $14.5 \mathrm{~cm} / \mathrm{s}$, $\mathrm{p}<0.001)$ and patients with anterior MI (12 and $14.5 \mathrm{~cm} / \mathrm{s}, \mathrm{p}<0.001)$. Patients with inferior Ml were divided into two subgroups: Those with and those without electrocardiographic signs of RV infarction. The tricuspid annular motion was significantly lower in patients with RV infarction than in patients without $\mathrm{RV}$ infarction (17 and $22.7 \mathrm{~mm}, \mathrm{p}<0.001)$. This controversy may be due to the exclusion of patients with RV infarction from our study, while Alam et al. study [13] did not exclude them.

In our study, there was a statistically significant relationship between RT ventricular dysfunction and the duration of ICU stay, we observed that patients with 
RV dysfunction had a prolonged ICU stay $(p<0.001)$. Jensen et al. in year 2010 [14] conducted a study on 50 patients admitted with STEMI, they assessed RT ventricular involvement by cardiac MRI and conducted that duration of ICU treatment was longer with the group of $\mathrm{RV}$ involvement than those without RV involvement did not differ significantly between the group with and that without $\mathrm{RV}$ involvement $(3 \pm 0.9,2.7 \pm 0.9$ days, respectively, $p=0.3$ ).

It was found in our results that RV dysfunction was related to the impairment of LV systolic function, and the relation was statistically significant $(p<0.001)$. This agreed with the study done by Antoni et al. 2010 [15], in which 621 consecutive patients admitted with AMI treated with primary $\mathrm{PCl}$ underwent echocardiography within $48 \mathrm{~h}$ of admission to assess left ventricular and RV function. Patients with congestive HF had significantly lower TAPSE (1.6 $\pm 0.2 \mathrm{~cm}$ vs. $1.7 \pm 0.2 \mathrm{~cm}, \mathrm{p}=0.01)$ and RV strain $(-19 \pm 6 \%$ vs. $-22 \pm 7 \%, p=0.02)$, also our results were similar to the results obtained by Konishi et al. 2013 [16], in which they proved a strong cor relationship between RV strains and longitudinal LV peak systolic strains.

We observed in our study that RV affection was significantly related to the RWMSI, the larger RWMSI value, the more RV affection $(p<0.001)$. This agreed with the results obtained from Keren Shahar et al., study in year 2016 [12], in which RWMSI was significantly higher in patients with RV dysfunction than patients with normal RV function $(p<0.001)$.

Our results revealed a significant statistical relationship between $\mathrm{RV}$ affection and in-hospital complications $(p<0.001)$ and 1 year mortality, $p=0.047$. This agreed with the study of Zornoff et al. They did a sub-study in year 2002 [17], in which two-dimensional echocardiograms were obtained in 416 patients with LV dysfunction LVEF $<$ or $=40 \%$ ) from the survival and ventricular enlargement echocardiographic study (mean $11.1 \pm 3.2$ days postinfarction). RV function assessed by the FAC was related to clinical outcome. They concluded that RV function is an independent predictor of death and the development of HF in patients with LV dysfunction after MI. Antoni et al. in year 2010 [15] found that RV FAC, TAPSE, and RV strain were all univariable predictors of worse outcomes in patients treated with primary $\mathrm{PCl}$ for $\mathrm{AMI}$.

In our study, there was a statistically significant correlation between RV longitudinal strain and RV-TAPSE as two echocardiographic methods for RV systolic function assessment $(r=0.792$ and $p<0.001)$, which agreed with the study of Kanar et al. 2017 [18], in which they assessed the effect of RV on early mortality in 81 patients with inferior $\mathrm{MI}$, it is worth noting that ROC analysis showed similar sensitivity and specificity values for RV strain and TAPSE in predicting early mortality in their study.

\section{Conclusion}

$\mathrm{RV}$ dysfunction is not uncommon in acute LV STEMI when using the definition of TAPSE $<17 \mathrm{~cm}$ and RV longitudinal strain less negative than $-19 \%$.

There was a significant relationship between $R V$ dysfunction and poor outcome in patients with acute LV STEMI.

Application of speckle-trackingechocardiography to conventional measurements of RT ventricular function by TAPSE could provide a more thorough and quantitative pathophysiological characterization of functional RV adaptation following MI.

\section{References}

1. Elzinga G, Van Grondelle R, Westerhof N, van den Bos GC Ventricular interference. Am J Physiol 1974;226(4):941-7. https://doi.org/10.1152/ajplegacy.1974.226.4.941 PMid:4823057

2. Ferlinz J, Gorlin R, Cohn PF, Herman MV. Right ventricular performance in patients with coronary artery disease. Circulation 1975;52(4):608-15. https://doi.org/10.1161/01.cir.52.4.608 PMid:1157272

3. Kostuk WJ, Kazamias TM, Gander MP, Simon AL, Ross J Jr. Left ventricular size after acute myocardial infarction: Serial changes and their prognostic significance. Circulation 1973;47:1174-9. https://doi.org/10.1161/01.cir.47.6.1174

PMid:4267843

4. Harrison A, Hatton N, Ryan JJ. The right ventricle under pressure: Evaluating the adaptive and maladaptive changes in the right ventricle in pulmonary arterial hypertension using echocardiography. Pulm Circ 2015;5(1):29-47. https://doi. org/10.1086/679699

PMid:25992269

5. Iparraguirre HP, Conti C, Grancelli H, Ohman EM, Calandrelli M, Volman S, et al. Prognostic value of clinical markers of reperfusion in patients with acute myocardial infarction treated by thrombolytic therapy. Am Heart J 1997;134(4):631-8. https:// doi.org/10.1016/s0002-8703(97)70045-0

PMid:9351729

6. Tamborini G, Muratori M, Brusoni D, Celeste F, Maffessanti F, Caiani EG, et al. Is right ventricular systolic function reduced after cardiac surgery? A two and three-dimensional echocardiographic study. Eur J Echocardiogr 2009;10:630. https://doi.org/10.1093/ejechocard/jep015

PMid:19252190

7. Fine NM, Chen L, Bastiansen PM, Frantz RP, Pellikka PA, Oh JK, et al. Outcome prediction by quantitative right ventricular function assessment in 575 subjects evaluated for pulmonary hypertension. Circ Cardiovasc Imaging 2013;6(5):711. https:// doi.org/10.1161/circimaging.113.000640

PMid:23811750

8. Saito K, Okura H, Watanabe N, Hayashida A, Obase K, Imai K, et al. Comprehensive evaluation of left ventricular strain using speckle tracking echocardiography in normal adults: Comparison of three-dimensional and two-dimensional approaches. J Am Soc Echocardiogr 2009;22:1025-30. https://doi.org/10.1016/j. 


\section{echo.2009.05.021}

PMid:19556106

9. Kjaergaard J, Petersen CL, Kjaer A, Schaadt BK, Oh JK Hassager C. Evaluation of right ventricular volume and function by $2 \mathrm{D}$ and $3 \mathrm{D}$ echocardiography compared to MRI. Eur J Echocardiogr 2006;7(6):430-8. https://doi.org/10.1016/j. euje.2005.10.009

PMid:16338173

10. Chan YH. Biostatistics102: Quantitative data parametric and non-parametric tests. Singapore Med J 2003;44:391-6.

PMid: 14700417

11. GorterTM, Lexis CP, HummelYM, Lipsic E, NijveldtR, Willems TP, et al. Right ventricular function after acute myocardial infarction treated with primary percutaneous coronary intervention (from the glycometabolic intervention as adjunct to primary percutaneous coronary intervention in ST-segment elevation myocardial infarction III trial). Am J Cardiol 2016;118(3):338-44. https://doi.org/10.1016/j.amjcard.2016.05.006

PMid:27265672

12. Shahar K, Darawsha W, Yalonetsky S, Lessick J, Kapeliovich M, Dragu $\mathrm{R}$, et al. Time dependence of the effect of right ventricular dysfunction on clinical outcomes after myocardial infarction: Role of pulmonary hypertension. J Am Heart Assoc 2016;5(7):e003606. https://doi.org/10.1161/jaha.116.003606 PMid:27402233

13. Alam M, Wardell J, Andersson E, Samad BA, Nordlander R. Right ventricular function in patients with first inferior myocardial infarction: Assessment by tricuspid annular motion and tricuspid annular velocity. Am Heart J 2000;139(4):710-5. https://doi. org/10.1016/s0002-8703(00)90053-x
PMid: 10740156

14. Jensen CJ, Jochims M, Hunold P, Sabin GV, Schlosser T, Bruder O. Right ventricular involvement in acute left ventricular myocardial infarction: Prognostic implications of MRI findings. AJR Am J Roentgenol 2010;194(3):592-8. https://doi. org/10.2214/ajr.09.2829

PMid:20173133

15. Antoni ML, Scherptong RW, Atary JZ, et al. Prognostic value of right ventricular function in patients after acute myocardial infarction treated with primary percutaneous coronary intervention. Circ Cardiovasc Imaging 2010;3(3):264-71. https:// doi.org/10.1161/circimaging.109.914366

PMid:20190280

16. Konishi K, Dohi K, Tanimura M, Sato Y, Watanabe K, Sugiura E, et al. Quantifying longitudinal right ventricular dysfunction in patients with old myocardial infarction by using speckle-tracking strain echocardiography. Cardiovasc Ultrasound 2013;11:23. https://doi.org/10.1186/1476-7120-11-23 PMid:23802850

17. Zornoff LA, Skali H, Pfeffer MA, SuttonMS, Rouleau JL, Lamas GA, et al. Right ventricular dysfunction and risk of heart failure and mortality after myocardial infarction. J Am Coll Cardiol 2002;39(9):1450-5. https://doi.org/10.1016/ s0735-1097(02)01804-1

PMid:11985906

18. Kanar BG, Tigen MK, Sunbul M, Cincin A, Atas H, Kepez A et al. The impact of right ventricular function assessed by 2-dimensional speckle tracking echocardiography on early mortality in patients with inferior myocardial infarction. Clin Cardiol 2018;41(3):413-8. https://doi.org/10.1002/clc.22890 PMid:29577346 